\title{
Expression Studies of Superoxide Dismutases in Nodules and Leaves of Transgenic Alfalfa Reveal Abundance of Iron-Containing Isozymes, Posttranslational Regulation, and Compensation of Isozyme Activities
}

\author{
Maria C. Rubio, ${ }^{1}$ Javier Ramos, ${ }^{1}$ K. Judith Webb, ${ }^{2}$ Frank R. Minchin, ${ }^{2}$ Esther González, ${ }^{3}$ \\ Cesar Arrese-Igor, ${ }^{3}$ and Manuel Becana ${ }^{1}$ \\ ${ }^{1}$ Departamento de Nutrición Vegetal, Estación Experimental de Aula Dei, Consejo Superior de \\ Investigaciones Científicas, Apdo. 202, 50080 Zaragoza, Spain; ${ }^{2}$ Institute of Grassland and \\ Environmental Research, Plas Gogerddan, Aberystwyth SY23 3EB, U.K.; ${ }^{3}$ Departamento de Ciencias del \\ Medio Natural, Universidad Pública de Navarra, 31006 Pamplona, Spain \\ Submitted 17 May 2001; Accepted 28 June 2001.
}

\begin{abstract}
The composition of antioxidant enzymes, especially superoxide dismutase (SOD), was studied in one nontransgenic and three transgenic lines of nodulated alfalfa plants. Transgenic lines overproduced MnSOD in the mitochondria of nodules and leaves (line 1-10), MnSOD in the chloroplasts (line 4-6), and FeSOD in the chloroplasts (line 10-7). In nodules of line 10-7, the absence of transgeneencoded FeSOD activity was due to a lack of mRNA, whereas in nodules of line 4-6 the absence of transgeneencoded MnSOD activity was due to enzyme inactivation or degradation. Transgenic alfalfa showed a novel compensatory effect in the activities of MnSOD (mitochondrial) and FeSOD (plastidic) in the leaves, which was not caused by changes in the mRNA levels. These findings imply that SOD activity in plant tissues and organelles is regulated, at least partially, at the posttranslational level. All four lines had low CuZnSOD activities and an abundant FeSOD isozyme, especially in nodules, indicating that FeSOD performs important antioxidant functions other than the scavenging of superoxide radicals generated in photosynthesis. This was confirmed by the detection of FeSOD cDNAs and proteins in nodules of other legumes such as cowpea, pea, and soybean. The cDNA encoding alfalfa nodule FeSOD was characterized and the deduced protein found to contain a plastid transit peptide. A comparison of sequences and other properties reveals that there are two types of FeSODs in nodules.
\end{abstract}

The superoxide dismutase (SOD) family of enzymes represents a primary line of defense against the superoxide radical and derived reactive oxygen species in all organisms.

Corresponding author: M. Becana; Telephone: +34-976-716055; Fax: +34 976 716145; E-mail: becana@eead.csic.es

Nucleotide sequences were deposited in the DDBJ/EMBL/GenBank databases under accession nos. AF377344 (Medicago sativa nodule FeSOD cDNA) and AF077224 (Vigna unguiculata nodule FeSOD cDNA).
Three types of SOD, differing in the metal at the active site, may coexist in plants. The CuZnSOD isozymes are localized in the cytosol, chloroplast stroma and intrathylakoidal space, glyoxysomal matrix, apoplast, nucleus, and mitochondrial intermembrane space; the MnSOD isozymes are localized in the mitochondrial and peroxisomal matrices and in the glyoxysomal membrane; and the FeSOD isozymes are localized in the chloroplast stroma (Bowler et al. 1994; del Río et al. 1992; Ogawa et al. 1996; Schinkel et al. 1998). Complete cDNA clones encoding some enzymes of each type have been isolated and used to construct transgenic plants overexpressing SODs in the chloroplasts, mitochondria, and cytosol (Bowler et al. 1991; Scandalios 1993; Van Camp et al. 1996). These studies were performed with model plants for transformation such as tobacco, but important crop legumes can now be transformed and regenerated with relative ease (Christou 1994). Because legumes are unique among crop plants in their ability to fix atmospheric $\mathrm{N}_{2}$ in symbiosis with rhizobia, transformation of these plants with antioxidant genes could provide additional advantages related to their protective role in nodule activity (Dalton et al. 1998; Matamoros et al. 1999; Puppo et al. 1982).

In this work, we analyzed the antioxidant composition of nodulated plants of the elite genotype N4 and three derived transgenic lines overproducing, respectively, MnSOD in the mitochondria, MnSOD in the chloroplasts, and FeSOD in the chloroplasts. Transgenic alfalfa plants showed a compensatory effect in expression of MnSOD and FeSOD in the leaves. All four lines displayed low CuZnSOD activities and abundant FeSOD and MnSOD activities in nodules and leaves. The cDNA encoding alfalfa nodule FeSOD was characterized and nodules of different legumes were screened for the presence of FeSOD cDNAs and proteins. Results show that the FeSODs of nodules belong to two types of enzymes, which can be distinguished biochemically and immunologically and are probably located in different subcellular compartments. 


\section{RESULTS}

\section{Composition of SOD isozymes \\ in alfalfa nodules and leaves.}

SOD activity staining of nondenaturing gels that were preincubated with potassium phosphate buffer alone or supplemented with $3 \mathrm{mM} \mathrm{KCN}$ or $5 \mathrm{mM} \mathrm{H}_{2} \mathrm{O}_{2}$ revealed that alfalfa nodules (Fig. 1) and leaves (Fig. 2) contain the three types of SOD that can be found in plants. These corresponded, in order of increasing mobility, to the MnSOD ( $\mathrm{KCN}$ insensitive, $\mathrm{H}_{2} \mathrm{O}_{2}$ insensitive), FeSOD ( $\mathrm{KCN}$ insensitive, $\mathrm{H}_{2} \mathrm{O}_{2}$ sensitive), and $\mathrm{CuZnSOD}$ (KCN sensitive, $\mathrm{H}_{2} \mathrm{O}_{2}$ sensitive) isozymes. Nodule extracts of all lines produced a single band of mitochondrial MnSOD activity (Fig. 1). However, in nodules and leaves of lines transformed to overproduce Nicotiana plumbaginifolia MnSOD in mitochondria (1-1, 1-6, 1-9, and 1-10), the MnSOD activity band was considerably more intense than in the nontransgenic line (Figs. 1 and 2), which probably reflects the inability of these gels to separate alfalfa and Nicotiana MnSODs. In contrast, in leaves of lines producing MnSOD in the chloroplasts (4-1, 4-6, and 4-7), two MnSODs were resolved (Fig. 2).

Nodules of all lines examined contained a distinct FeSOD isozyme, which also was present, albeit at lower levels, in the leaves (compare Figs. 1B and 2B). The presence of abundant FeSOD activity in alfalfa nodules and leaves is in clear contrast with previous reports showing no FeSOD in leaves (McKersie et al. 1999; McKersie et al. 2000). Extracts of leaves from lines transformed to produce Arabidopsis thaliana FeSOD in the chloroplasts (10-4 and 10-7) showed three extra bands of FeSOD activity (Fig. 2). In contrast, there were four $\mathrm{CuZnSOD}$ isozymes in the nodules, the first two (according to relative mobility) at higher levels than in the leaves (Fig. 1). Nodules also had a major band showing SOD activity, which was labeled X. This band accounted for $70 \%$ of total activity (calculated from data in Table 1) and was assigned to the MnSOD type (KCN insensitive, $\mathrm{H}_{2} \mathrm{O}_{2}$ insensitive). Its electrophoretic mobility (similar to that of plant FeSODs) and apparent molecular mass (45 kDa), however, are clearly different from those of typical plant MnSODs (Sevilla et al. 1982). It is possible that at least part of the activity of band $\mathrm{X}$ is due to bacteroid MnSOD. Thus, activity stain gels of extracts from highly purified bacteroids, broken by sonication, revealed a single MnSOD isozyme exhibiting identical mobility to band $\mathrm{X}$ (Fig. 1).

\section{Transcripts of SOD isozymes in alfalfa nodules and leaves.}

Out of the nine lines screened initially, we selected line N4 and three transgenic lines (1-10, 4-6, and 10-7) for further study. These lines represented each different construct. Expression of $M n S O D$ and $F E S O D$ genes in the nodules and leaves of the four selected lines was analyzed by reverse-transcription polymerase chain reaction (RT-PCR) and Northern blots. Gene-specific primers were used to distinguish the mRNAs encoded by the endogenous genes (alfalfa MnSOD and FeSOD) and the transgenes (Nicotiana MnSOD and Arabidopsis FeSOD).

Consistent with activity data (Fig. 1), RT-PCR analysis revealed that the absence of Arabidopsis FeSOD activity in the nodules of line 10-7 was due to a lack of message, whereas the absence of Nicotiana MnSOD activity in the nodules of line 4-6 was probably a result of inactivation or degradation of the enzyme because the corresponding mRNA was detectable at levels similar to those in line 1-10 (Fig. 3). The analysis also showed that the leaves of all four lines express endogenous MnSOD and FeSOD, the leaves of lines 1-10 and 4-6 express Nicotiana MnSOD, and the leaves of line 10-7 express Arabidopsis FeSOD (Fig. 3).

Northern blot analysis of the steady-state mRNA levels confirmed the presence of an abundant message for endogenous MnSOD and FeSOD in nodules and leaves of all four lines as well as the absence of Arabidopsis FeSOD mRNA in nodules of line 10-7 and its presence in the corresponding leaves (Fig. 4). Interestingly, Northern blots showed abundant mRNA for Nicotiana MnSOD in the leaves of line 4-6 and less abundant mRNA in the leaves of line 1-10. The two mRNAs were also present in the corresponding nodules (Fig. 4). The differences in mRNA size between the Nicotiana MnSODs targeted to chloroplasts (line 4-6) and to mitochondria (line 1-10) reflect the differences in the original constructs, with the chloroplast transit peptide being significantly larger than the mitochondrial peptide (Bowler et al. 1991).

\section{Antioxidant enzymes of alfalfa nodules and leaves.}

The activities of SOD and other antioxidant enzymes were measured in the four selected lines. The antioxidant activities of nodules from control plants were determined with optimized methods, including specific controls to ensure measurement of genuine activities in the presence of leghemoglobin, which may interfere with determination of guaiacol peroxidase (GPX) or SOD activity under certain conditions (Puppo et al. 1982). There were no significant differences in total SOD activity or in the activities of the $\mathrm{H}_{2} \mathrm{O}_{2}$-scavenging enzymes in nodules for any of the four lines. However, when MnSOD and FeSOD activities were individualized by densitometry, MnSOD activity in line 110 was found to be $45 \%$ higher than in line N4 and FeSOD activity of line 4-6 was 32\% higher (Table 1).

Total SOD, ascorbate peroxidase (APX), GPX, and catalase activities were similar in leaves of all lines except line 10-7, which exhibited a total SOD activity that was $39 \%$ higher than in line N4 (Table 2). Separate quantification of SOD isozymes showed that the leaves of lines 1-10 and 4-6 had approximately 20\% more MnSOD activity and $40 \%$ less FeSOD activity. Conversely, the leaves of line 10-7 had 37\% less MnSOD activity and twice as much FeSOD activity. These results confirmed that the leaves of the transformed plants expressed the MnSOD or FeSOD encoded by the transgenes.

\section{Characterization of the FeSOD cDNA and deduced protein of alfalfa nodules.}

The finding of abundant FeSOD activity in alfalfa nodules and the absence of sequences for any FeSOD from nonphotosynthetic tissue prompted us to isolate and characterize the corresponding cDNA. Degenerate primers were used to screen an alfalfa nodule cDNA library. As expected, the positive clones contained the $5^{\prime}$ and $3^{\prime}$ regions of an FeSOD cDNA, judging by the high homology (>70\% identity) with other cDNAs encoding FeSODs from higher plants. The complete cDNA sequence of alfalfa nodules (Fig. 5) contains 10 nucleotides within the $5^{\prime}$ untranslated region (UTR), 942 nucleotides within the open reading frame (ORF), and 205 nucleotides within the $3^{\prime}$ UTR that 
precedes a poly $(\mathrm{A})^{+}$tail. The $3^{\prime}$ end also contains a consensus signal for polyadenylation.

The ORF encodes a protein of 313 amino acids (Fig. 5), with a calculated molecular mass of $35.4 \mathrm{kDa}$ and isoelectric point of 5.79. The enzyme contains the residues thought to be essential for FeSOD activity (Tyr-91, Trp-133, and Asn-218) and metal binding (His-83, His-135, Asp-235, and His-239) as well as the residues (Ala-130, Gln-131, Trp-133, and Ala-219) proposed as primary candidates to distinguish FeSODs from MnSODs (Bowler et al. 1994; Van Camp et al. 1990). The deduced protein of alfalfa nodules also contains a signal peptide that, on the basis of N-terminal sequences of other FeSODs (Van Camp et al. 1990), is 57 amino acid residues long (Fig. $5)$. The signal peptide is very rich in serine (19\%) and threonine (11\%) compared with arginine (5\%) and is devoid of glutamic acid, aspartic acid, and tyrosine. All of these charac-
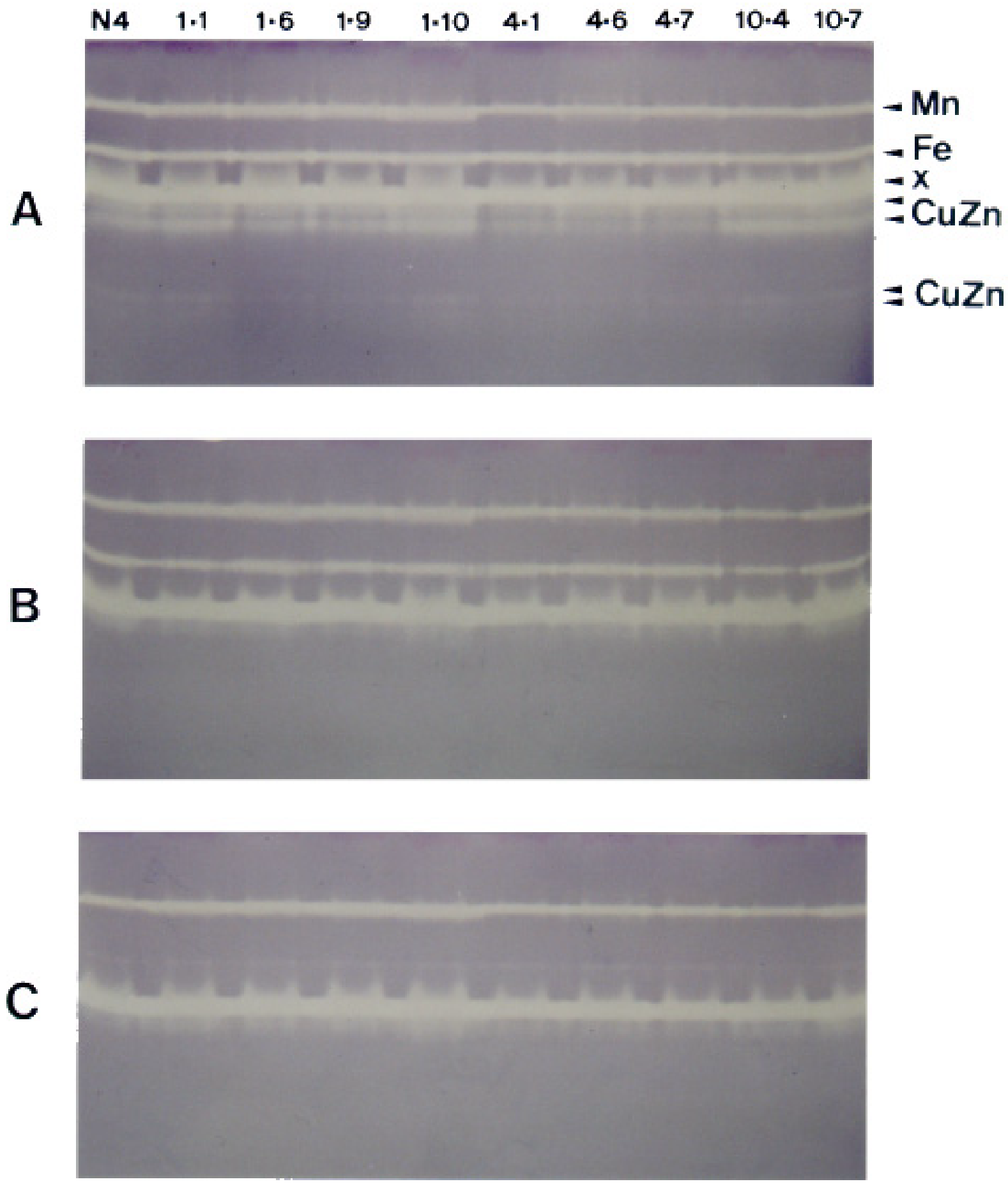

Fig. 1. Isozyme superoxide dismutase composition of nodules from alfalfa line $\mathrm{N} 4$ and derived transgenic lines. Prior to activity staining, the gels were incubated with $\mathbf{A}$, potassium phosphate buffer, $\mathbf{B}$, buffer plus $3 \mathrm{mM} \mathrm{KCN}$, or $\mathbf{C}$, buffer plus $5 \mathrm{mM} \mathrm{H}_{2} \mathrm{O}_{2}$. Lanes were loaded with $40 \mu \mathrm{g}$ of protein. 
teristics are typical of plastid transit peptides (von Heijne et al. 1989). The mature protein has a calculated molecular mass of $29.4 \mathrm{kDa}$ and an isoelectric point of 5.09, which is significantly different from the values predicted (molecular mass of 23.0 to $25.3 \mathrm{kDa}$; isoelectric point of 5.42 to 6.07 ) for the FeSODs of other plants. The deduced amino acid sequence of alfalfa nodule FeSOD has high homology (>70\%) with the FeSODs from other higher plants and lower homology $(<70 \%)$ with the enzymes from cyanobacteria and green algae.
The nodule enzyme, however, only showed $58 \%$ identity with Arabidopsis FeSOD isozyme-1 and 50\% identity with rice FeSOD.

Because FeSODs are detected only occasionally in plants, we screened extracts of other legume nodules for the presence of FeSOD. This provided information on the distribution and abundance of the enzyme and allowed a comparison with the alfalfa nodule FeSOD. We used SOD activity gels and found FeSOD in nodules of cowpea, mungbean, pea, bean, and soy-
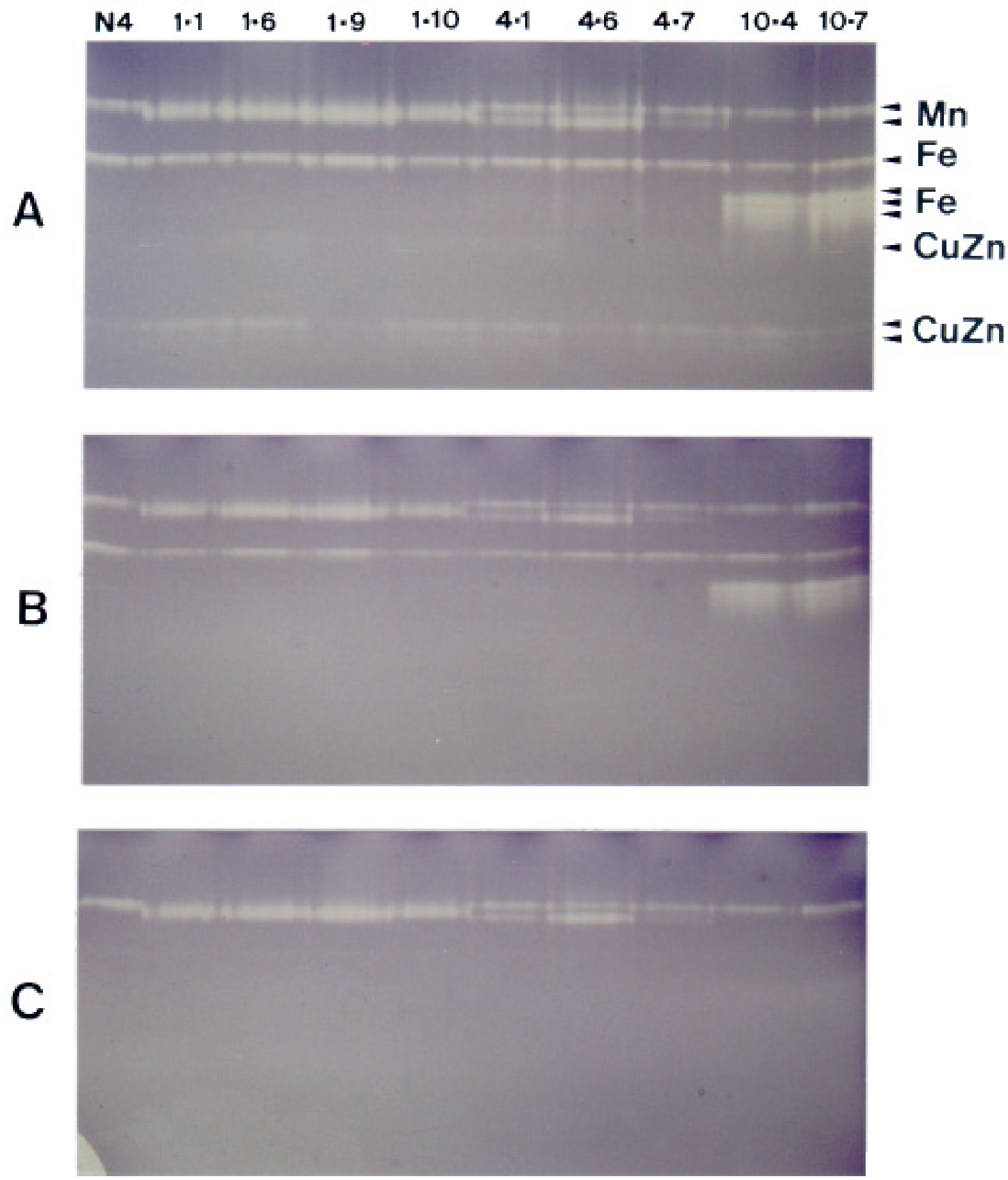

Fig. 2. Isozyme superoxide dismutase composition of leaves from alfalfa line N4 and derived transgenic lines. Panel description is identical to that of Figure 1. Lanes were loaded with $40 \mu \mathrm{g}$ of protein. 
bean but not in those of lupine and broad bean (data not shown). The same primers used for alfalfa served to isolate clones and obtain the complete cDNA sequence of cowpea nodule FeSOD as well as partial sequences for pea and soybean nodule FeSODs. All derived protein sequences were used to construct a phylogenetic tree of known FeSODs (Fig. 6). It is interesting to note that three isozymes have been described for Arabidopsis and that the partial sequence we found for soybean nodules differs from that reported for leaves, suggesting that FeSOD may be present as a multigenic family, at least in some plants. Phylogenetic analysis revealed three large clusters, which, as expected, are fully consistent with homology data: a cluster including the FeSODs of cyanobacteria, green algae, rice, and Arabidopsis isozyme-1; a cluster including the FeSOD of Raphanus and Arabidopsis isozyme2; and a cluster including legume FeSODs. Interestingly, in this third cluster two groups can be recognized (Fig. 6), which appears to correlate with subcellular localization. Prediction programs reveal that the FeSODs of alfalfa and pea nodules contain a plastid signal peptide, whereas the FeSODs of cow- pea nodules and soybean leaves and nodules lack any recognizable plastid peptide. The presence of two types of FeSODs in nodules is confirmed by the absence of cross-reactivity between an antibody raised to cowpea nodule FeSOD and alfalfa or pea nodule FeSODs (data not shown).

\section{DISCUSSION}

In this work, we report that all three types of SODs are present in nodules and leaves of alfalfa (Figs. 1 and 2). The isozymic composition of SOD in our extracts (low CuZnSOD activity, high FeSOD activity) clearly contrasts with that reported by other authors (McKersie et al. 2000) for alfalfa leaves (high CuZnSOD activity, virtually no FeSOD activity). These differences may be the result of variations in plant development or nutritional factors such as the nitrogen source ( $\mathrm{N}_{2}$ versus combined nitrogen) and the micronutrient supply, which is known to differentially affect expression of SOD isozymes (Kurepa et al. 1997). Whatever the reason, our results indicate that important variations in the SOD isozyme

\section{NODULES}

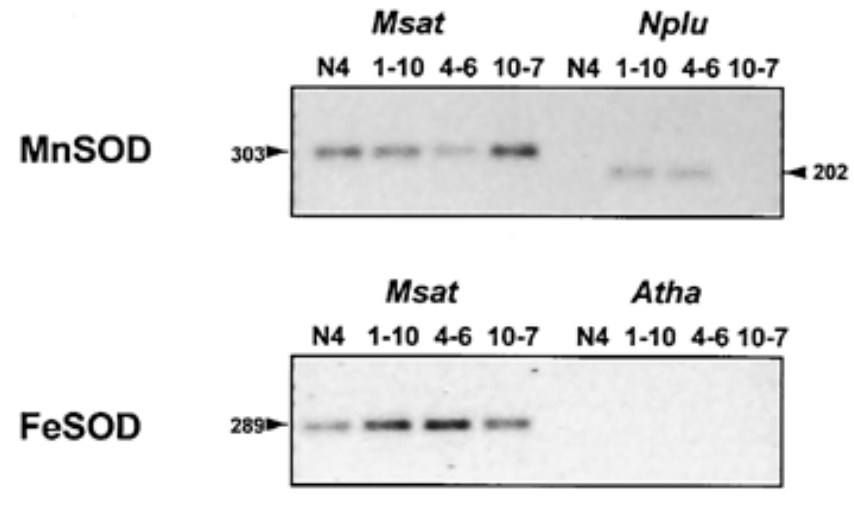

N4 $\quad \begin{array}{llll}1-10 & 4-6 & 10-7\end{array}$

Ubiquitin

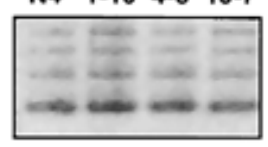

\section{LEAVES}

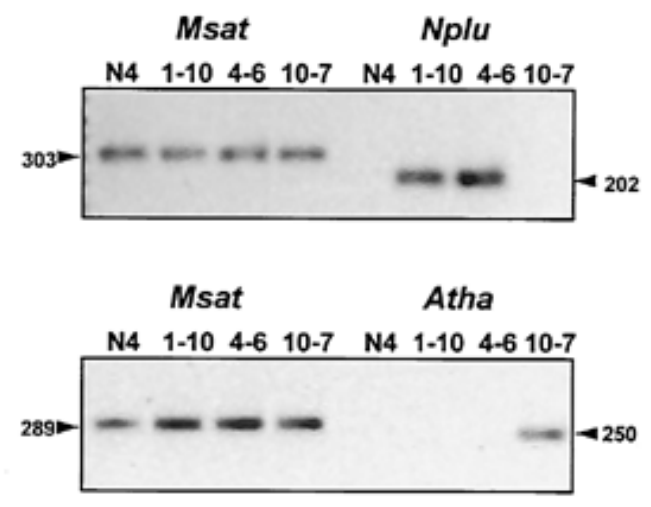

Fig. 3. Reverse-transcription polymerase chain reaction (PCR) analysis of superoxide dismutase (SOD) isozymes of alfalfa nodules and leaves. Genespecific primers were used to distinguish mRNAs of alfalfa (Medicago sativa [Msat] MnSOD and Msat FeSOD) and mRNAs encoded by the transgenes (Nicotiana plumbaginifolia [Nplu] MnSOD and Arabidopsis thaliana [Atha] FeSOD). Size of PCR products is indicated in base pairs. To ensure uniform amounts of template, PCR reactions were performed simultaneously with ubiquitin primers (Horvath et al. 1993).

Table 1. Antioxidant enzyme activities in nodules of line N4 and three derived transgenic lines of alfalfa ${ }^{\mathrm{z}}$

\begin{tabular}{|c|c|c|c|c|}
\hline Enzyme & N4 & $1-10$ & 4-6 & $10-7$ \\
\hline Total superoxide dismutase (SOD) & $11.29 \pm 1.59 \mathrm{a}$ & $13.43 \pm 0.66 \mathrm{a}$ & $13.03 \pm 1.03 \mathrm{a}$ & $12.09 \pm 0.38 \mathrm{a}$ \\
\hline MnSOD & $2.02 \pm 0.15 \mathrm{a}$ & $2.93 \pm 0.38 \mathrm{~b}$ & $2.22 \pm 0.33 \mathrm{ab}$ & $2.32 \pm 0.16 \mathrm{ab}$ \\
\hline FeSOD & $1.30 \pm 0.14 \mathrm{ab}$ & $1.59 \pm 0.24 \mathrm{ab}$ & $1.71 \pm 0.03 \mathrm{~b}$ & $1.08 \pm 0.19 \mathrm{a}$ \\
\hline Ascorbate peroxidase (APX) & $92.7 \pm 6.8 \mathrm{a}$ & $99.1 \pm 11.2 \mathrm{a}$ & $104.3 \pm 12.5 \mathrm{a}$ & $87.8 \pm 11.8 \mathrm{a}$ \\
\hline Guaiacol peroxidase (GPX) & 683. $\pm 45 \mathrm{a}$ & 825. $\pm 111 \mathrm{a}$ & 820. $\pm 101 \mathrm{a}$ & 805. $\pm 69 \mathrm{a}$ \\
\hline Catalase & $8.9 \pm 0.8 \mathrm{a}$ & $9.1 \pm 1.1 \mathrm{a}$ & $8.4 \pm 1.5 \mathrm{a}$ & $7.1 \pm 1.0 \mathrm{a}$ \\
\hline Protein & 182. $\pm 6 \mathrm{a}$ & 198. $\pm 16 \mathrm{ab}$ & 212. $\pm 10 \mathrm{ab}$ & 220. $\pm 18 \mathrm{~b}$ \\
\hline
\end{tabular}

${ }^{\mathrm{z}}$ Units are as follows: SOD (units per mg of dry weight), APX and GPX ( $\mu \mathrm{mol}$ per min per g of dry weight), catalase (mmol per min per g of dry weight), and protein (mg per $\mathrm{g}$ of dry weight). Means \pm standard error of the means $(n=4-7)$ were compared using one-way analysis of variance and the Duncan's multiple range test. For each parameter, means followed by the same letter do not differ significantly at $P<0.05$. 
pattern do not affect the health and growth of plants. This may well reflect compensation in the activities of the SOD isozymes, which would require their expression to be tightly regulated. Thus, overproduction of MnSOD in the leaves of lines 1-10 and 4-6 was matched by lower FeSOD activities, resulting in similar total SOD activities in the leaves of the two lines and the nontransgenic line (Table 2). Conversely, overproduction of FeSOD in line 10-7 was paralleled by a lowering in MnSOD activity, although in this case the twofold excess of the former was not compensated for completely and the total SOD activity of the leaves in line 10-7 remained $40 \%$ greater than in line N4. Northern analysis indicated that the compensation of activities is not due to changes in transcript abundance. Thus, the mRNA level of endogenous MnSOD in leaves of line 10-7, which expresses Arabidopsis FeSOD, is even higher than in line N4, and the mRNA level of endogenous FeSOD in lines 1-10 and 4-6, which express Nicotiana MnSOD, is similar to or higher than in line N4 (Fig. 4).
Therefore, the compensation between MnSOD and FeSOD activities occurs, at least in part, at the posttranslational level.

In nodules, only line 1-10 produced the transgene-encoded SOD (Fig. 1). The Nicotiana MnSOD mRNAs, however, were found in both lines 1-10 and 4-6, albeit at low levels (Figs. 3 and 4). The absence of Nicotiana MnSOD activity in nodules of line 4-6, despite expression of the gene, can be attributed to degradation of the enzyme, perhaps as a result of the inability of nodule plastids to process the protein bearing a chloroplastic signal peptide. Another surprising observation is the absence of a transcript for Arabidopsis FeSOD in nodules of line 10-7, despite its abundance in the corresponding leaves. This may be ascribed, at least in part, to a weak activity of the $35 \mathrm{~S}$ promoter in alfalfa nodules. This still does not explain, however, why constructs with identical promoter and chloroplastic targeting sequences are expressed (MnSOD in line 4-6) or not expressed (FeSOD in line 10-7) in nodules. To verify the differences in expression among the three transgenic lines, nodules of

\section{NODULES}

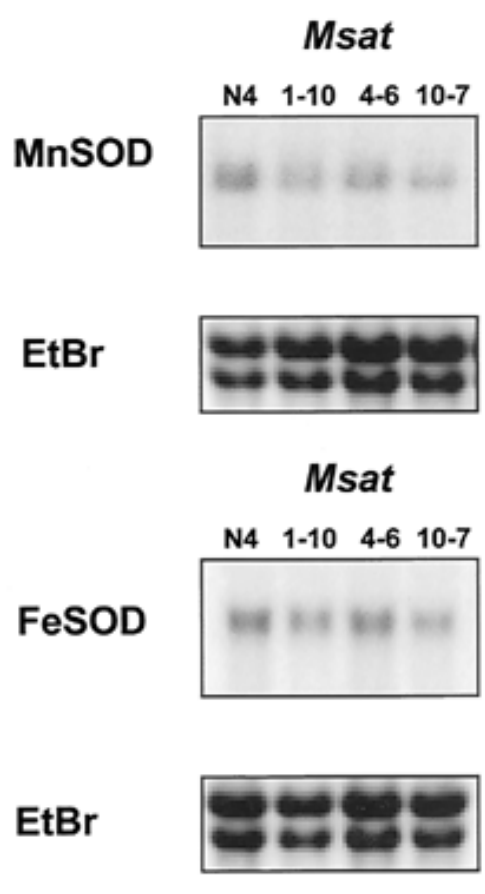

Nplu

N4 $\quad 1-10 \quad 4-6 \quad 10-7$
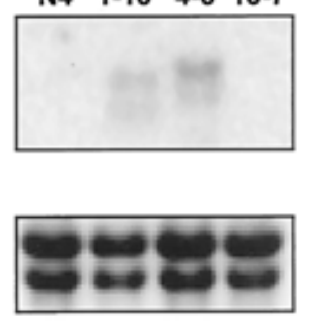

Atha

N4 $\quad \begin{array}{llll}1-10 & 4-6 & 10-7\end{array}$
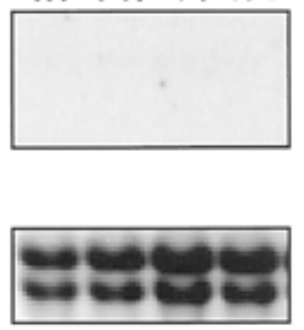

LEAVES

Msat

$\begin{array}{llll}\text { N4 } & 1-10 \quad 4-6 & 10-7\end{array}$
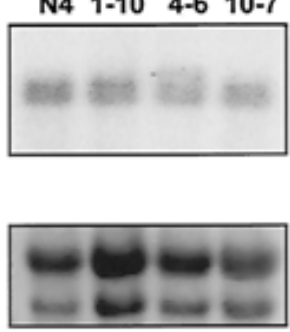

Msat

$\begin{array}{llll}\text { N4 } & 1-10 & 4-6 & 10-7\end{array}$
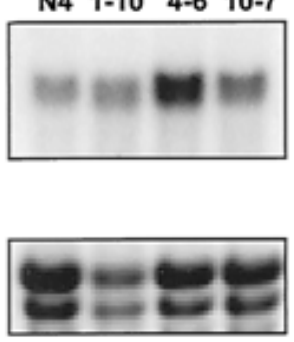

Nplu

$\begin{array}{llll}\text { N4 } & 1-10 & 4-6 & 10-7\end{array}$
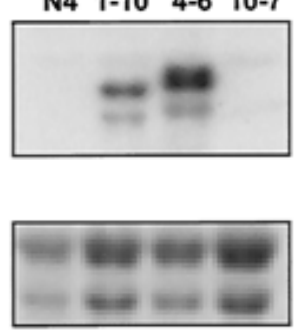

Atha
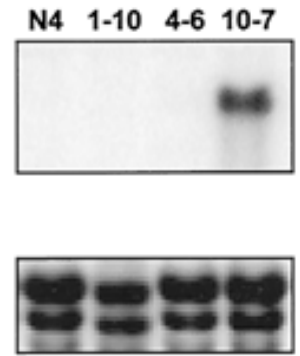

Fig. 4. Northern blot analysis of superoxide dismutase isozymes of alfalfa nodules and leaves. Probes were generated from the primers used for reversetranscription polymerase chain reaction. All bands were the expected 1,100-1,200 bp according to RNA molecular weight markers. Uniform loading and integrity of RNA was verified by spectrophotometry and visualization of RNA with ethidium bromide (EtBr).

Table 2. Antioxidant enzyme activities in leaves of line N4 and three derived transgenic lines of alfalfa ${ }^{\mathrm{z}}$

\begin{tabular}{lcccc}
\hline Enzyme & N4 & $\mathbf{1 - 1 0}$ & $\mathbf{4 - 6}$ & $\mathbf{1 0 - 7}$ \\
\hline Total superoxide dismutase (SOD) & $2.86 \pm 0.14 \mathrm{a}$ & $2.77 \pm 0.15 \mathrm{a}$ & $2.96 \pm 0.15 \mathrm{a}$ & $3.98 \pm 0.11 \mathrm{~b}$ \\
MnSOD & $1.52 \pm 0.14 \mathrm{a}$ & $1.80 \pm 0.13 \mathrm{~b}$ & $1.88 \pm 0.21 \mathrm{~b}$ & $0.96 \pm 0.10 \mathrm{c}$ \\
FeSOD & $1.18 \pm 0.11 \mathrm{a}$ & $0.64 \pm 0.08 \mathrm{~b}$ & $0.75 \pm 0.31 \mathrm{~b}$ & $2.40 \pm 0.14 \mathrm{c}$ \\
Ascorbate peroxidase & $63.2 \pm 5.4 \mathrm{a}$ & $49.1 \pm 8.3 \mathrm{a}$ & $67.1 \pm 7.2 \mathrm{a}$ & $63.9 \pm 10.2 \mathrm{a}$ \\
Guaiacol peroxidase & $259 . \pm 11 \mathrm{a}$ & $188 . \pm 14 \mathrm{~b}$ & $233 . \pm 11 \mathrm{a}$ & 238. \\
Catalase & $0.67 \pm 0.22 \mathrm{a}$ & $0.63 \pm 0.20 \mathrm{a}$ & $0.58 \pm 0.14 \mathrm{a}$ & $0.58 \pm 0.09 \mathrm{a}$ \\
Protein & $163 . \quad \pm 6 \mathrm{a}$ & $169 . \pm 8 \mathrm{a}$ & $204 . \pm 15 \mathrm{~b}$ & 209. \\
\hline
\end{tabular}

${ }^{\mathrm{z}}$ Enzyme units and statistical analysis of means \pm standard error of the means $(n=4-5)$ are as in Table 1. For each parameter, means followed by the same letter do not differ significantly at $P<0.05$. 
exactly the same plant were used to extract RNA (for Northern analysis) and protein (for activity gel analysis). This experiment confirmed that nodules of line 1-10 expressed transcript and activity, nodules of line 4-6 expressed transcript but not activity, and nodules of line 10-7 did not express the transcript.
The abundance of FeSOD in alfalfa nodules deserved special attention because this type of SOD, in contrast to $\mathrm{CuZnSOD}$ and MnSOD, is not ubiquitous in plants. Furthermore, there are contradictory reports about the presence of FeSOD in leaves of some species such as common bean and

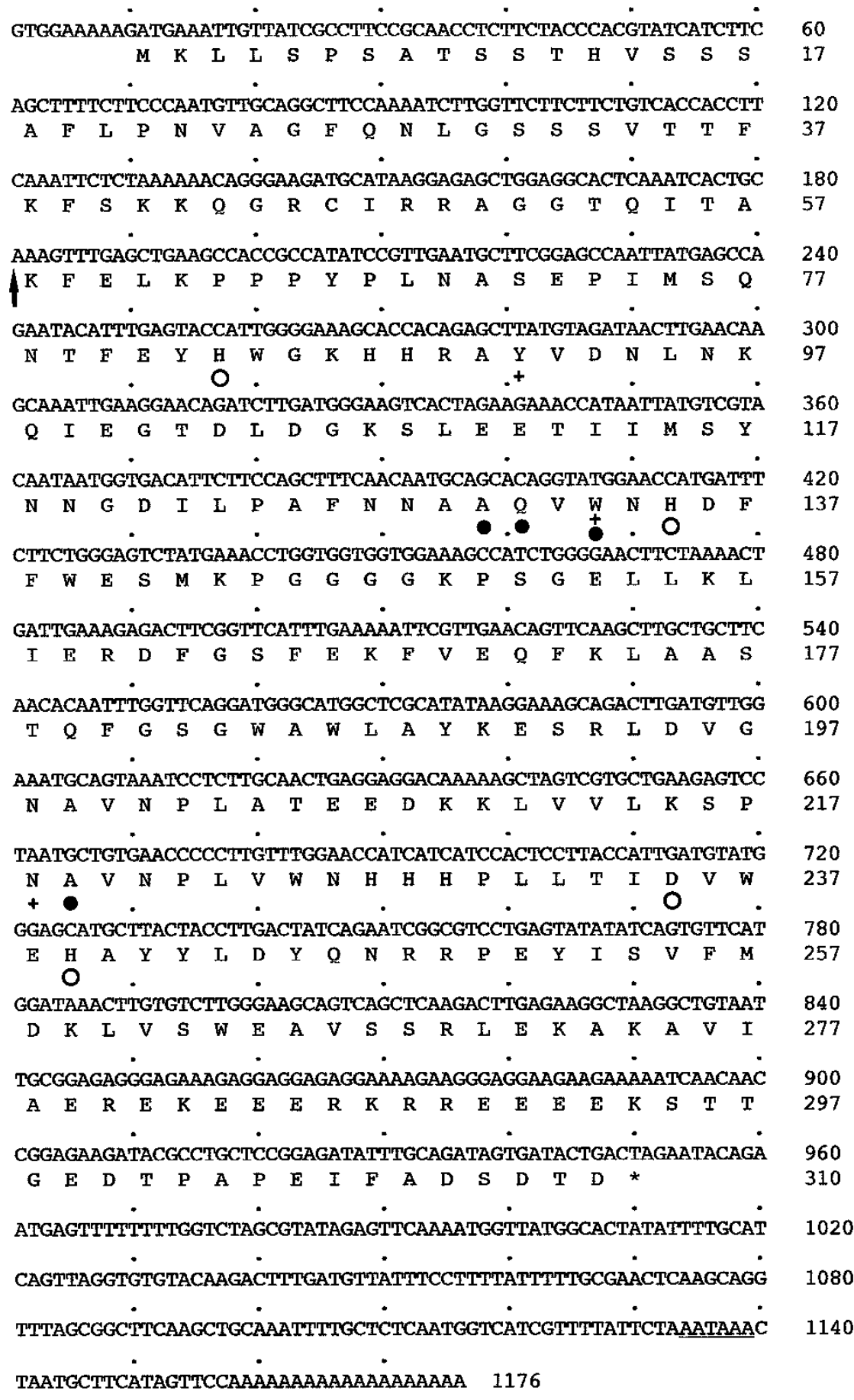

Fig. 5. Nucleotide and deduced amino acid sequences of FeSOD from alfalfa nodules. The arrow indicates the putative cleavage site of the signal peptide. Residues that distinguish FeSOD from MnSOD are indicated with a black circle. Residues essential for catalytic activity and metal binding are indicated with a plus mark and a white circle, respectively. A putative polyadenylation sequence at the $3^{\prime}$ end is underlined. 
cowpea. Early studies reported that FeSODs were confined to a few families of higher plants (Bridges and Salin 1981). It seems now, however, that the gene is more widely distributed than previously thought but remains silent due to a lack of appropriate inducing conditions (Bowler et al. 1994). Our finding of FeSOD in nodules of healthy plants of alfalfa and other legumes is consistent with this hypothesis. The FeSODs of alfalfa and pea nodules are closely related and synthesized as precursor plastidic proteins, which suggests that these enzymes play a role in plastid metabolism other than the scavenging of superoxide radicals associated with photosynthesis. The occurrence of abundant ferritin in the plastids may ensure an adequate iron supply for the synthesis of FeSOD, especially under conditions in which this isozyme is up-regulated (Becana et al. 1998). The presence of at least two types of FeSODs further underscores the multifaceted nature of antioxidant protection in nodules and suggests that the various SOD isozymes may have evolved to perform specific defensive or regulatory roles that are essential for optimal nodule functioning. Clearly, additional work is necessary to characterize these roles.

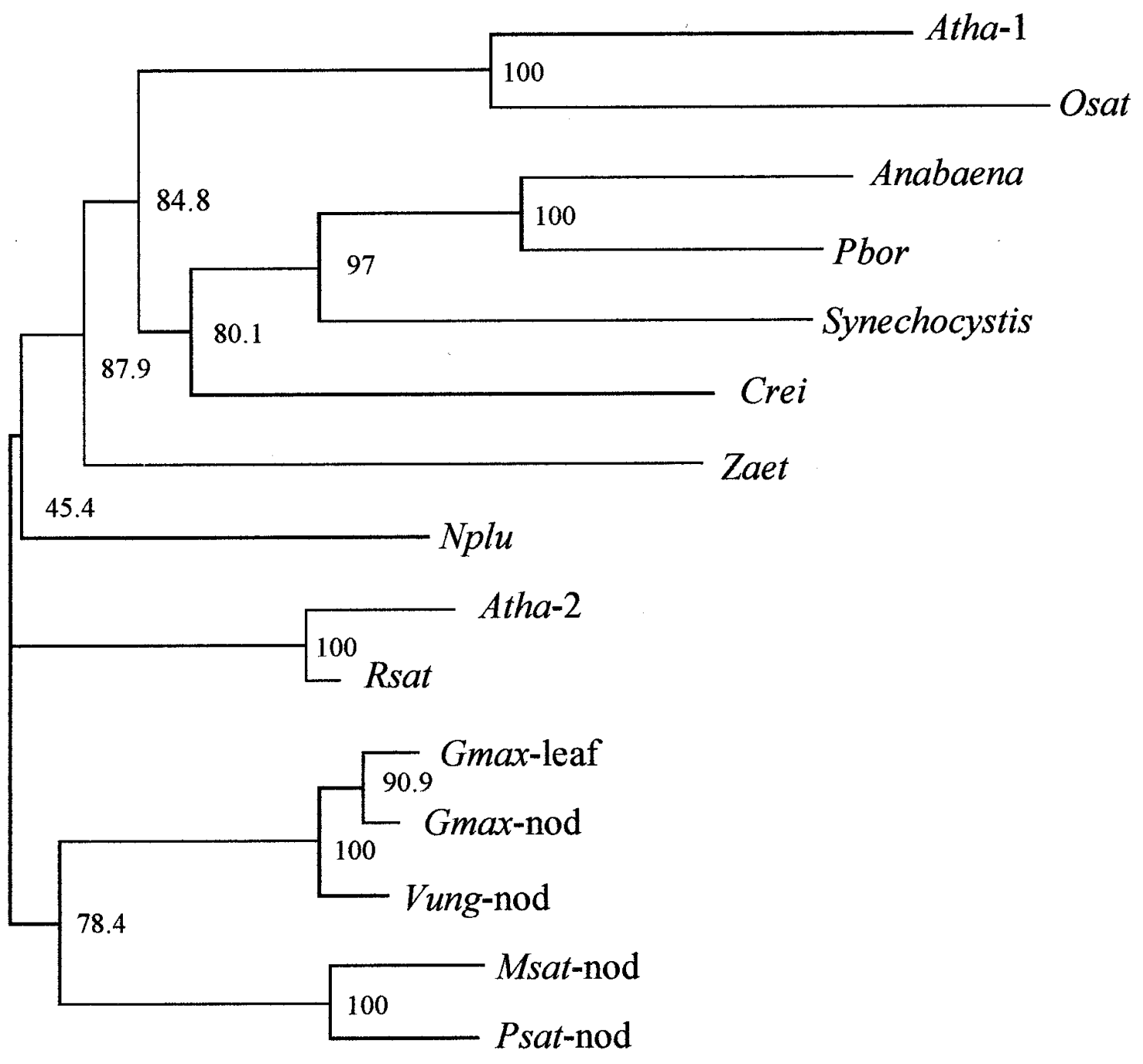

0.01

Fig. 6. Unrooted phylogenetic tree of FeSOD proteins from cyanobacteria, green algae, and higher plants. Tree was calculated with the neighbor-joining method from the CLUSTAL W program suite. Numbers correspond to percentages of 1,000 "bootstraps." Bar represents 0.01 substitutions per site. Abbreviations and DDBJ/EMBL/GenBank accession nos. are: Anabaena, Anabaena strain PCC7120 (AF173990); Atha-1, Arabidopsis thaliana isozyme-1 (AF061852); Atha-2, Arabidopsis thaliana isozyme-2 (P21276); Crei, Chlamydomonas reinhardtii (JC4611); Gmax-leaf, Glycine max, leaf isozyme (M64267); Gmax-nod, Glycine max nodule isozyme (partial sequence); Msat-nod, Medicago sativa nodules (AF377344); Nplu, Nicotiana plumbaginifolia (A39267); Osat, Oryzae sativa (AB014056); Pbor, Plectonema boryanum (P50061); Psat-nod, Pisum sativum (partial sequence); Rsat, Raphanus sativus (AF061583); Synechocystis, Synechocystis strain PCC6803 (P77968); Vung-nod, Vigna unguiculata nodules (AF077224); Zaet, Zantedeschia aethiopica (AF094831). 


\section{MATERIALS AND METHODS}

\section{Plant material and propagation.}

Alfalfa (Medicago sativa L.) clones used in this study were provided by B. McKersie. Clone N4 is the nontransgenic parental line. Clones 1-1, 1-6, 1-9, and 1-10 were transformed with pSOD1, which was generated as a transcriptional fusion of the MnSOD preprotein from $N$. plumbaginifolia to the cauliflower mosaic virus 35S promoter (Bowler et al. 1991). Clones 4-1, 46, and 4-7 were transformed with pSOD4, which harbors the mature MnSOD-encoding sequence of $N$. plumbaginifolia fused to a chloroplast transit peptide sequence (small subunit of Rubisco from pea) under control of the $35 \mathrm{~S}$ promoter (Bowler et al. 1991). Clones 10-4 and 10-7 were transformed with pSOD10, which encodes FeSOD from $A$. thaliana and is coupled to the same chloroplast targeting sequence under control of the $35 \mathrm{~S}$ promoter (Van Camp et al. 1996). All three binary vectors (pSOD1, pSOD4, and pSOD10) contained the nptII gene as a selectable marker under control of the nopaline synthase (nos) promoter (Herrera-Estrella et al. 1983).

Briefly, the transformation procedure was as follows. Alfalfa petiole explants from the parental line were co-cultivated with Agrobacterium tumefaciens C58C1 pMP90 for 3 days in the dark on SH induction medium (McKersie et al. 2000; Van Camp et al. 1996). The explants were plated on SH medium containing $50 \mathrm{mg}$ of kanamycin per liter, and somatic embryos were matured on BOi2Y development medium containing sucrose but no growth regulators or antibiotics (McKersie et al. 2000). Putative transformants were screened for the presence of T-DNA by PCR. Positive plants were transplanted to growth medium in a greenhouse and screened by determining SOD activity in leaf extracts and isozyme composition on nondenaturing gels (McKersie et al. 2000). Clones were propagated vegetatively by cuttings taken from plants before flowering, briefly dipped into commercial hormone rooting powder, and placed in beakers containing nutrient solution supplemented with $1 \mathrm{mM} \mathrm{KNO}_{3}$. Cuttings were left to root in the growth cabinet under low-light conditions for approximately 25 days. At that time, plants were transferred to pots containing a perlite-vermiculite mixture and watered once with nutrient solution supplemented with $2 \mathrm{mM} \mathrm{KNO}$. After 3 and 7 days, plants were inoculated twice with Sinorhizobium meliloti 102F78. Growth conditions were the same as described previously (Gogorcena et al. 1997). No obvious phenotypic differences between the transgenic and the parental lines were observed.

\section{Isolation of FeSOD cDNA of alfalfa nodules.}

An alfalfa nodule cDNA $\lambda$ ZAP library (a gift from $C$. P. Vance) was PCR screened with degenerate oligonucleotide primers (forward: 5'-GC[A/T]TTCAACAA[T/C]GC[T/A]GC[T/A]CAGG-3'; reverse: 5'-TC[A/C]AG[G/A]TAGTAAGCATGCTCCCA-3') based on conserved sequences of FeSODs (DDBJ/EMBL/GenBank accession nos. in parentheses) from Chlamydomonas reinhardtii (U22416), N. plumbaginifolia (M55909), A. thaliana isozyme-2 (P21276), and soybean leaves (M64267). The 5' and 3' end regions were amplified with the above primers in combination with T3 $\left(5^{\prime}\right.$ GCAATTAACCCTCACTAAAGGG-3') and T7 (5'-GCGTAATACGACTCACTATAGGGC-3') primers. The PCR mix contained $0.2 \mu \mathrm{M}$ primers, $240 \mu \mathrm{M}$ deoxynucleoside triphos- phate (dNTP), $1.5 \mathrm{mM} \mathrm{MgCl} 2,0.05 \% \mathrm{~W}-1$ detergent (Life Technologies, Paisley, U.K.), and $1.25 \mathrm{U}$ of Taq polymerase (Life Technologies) in a final volume of $25 \mu \mathrm{l}$ of the PCR buffer (20 mM Tris-HCl, pH 8.4; $50 \mathrm{mM} \mathrm{KCl).} \mathrm{The} \mathrm{PCR} \mathrm{cy-}$ cling protocol consisted of an initial denaturation step at $95^{\circ} \mathrm{C}$ for $3 \mathrm{~min} ; 40$ cycles of $62^{\circ} \mathrm{C}$ for $45 \mathrm{~s}, 72^{\circ} \mathrm{C}$ for $60 \mathrm{~s}$, and $95^{\circ} \mathrm{C}$ for $45 \mathrm{~s}$; and a final elongation step at $72^{\circ} \mathrm{C}$ for $10 \mathrm{~min}$.

The resulting PCR products were size fractionated on $1 \%$ agarose gels, purified (Concert; Life Technologies), and subcloned into the linearized vector pGEM-T Easy (Promega, Madison, WI, U.S.A.). The DNA inserts from several clones were sequenced on both strands with an ABI Prism 377 sequencer (Applied Biosystems, Foster City, CA, U.S.A.). Homology searches were performed with the BLAST algorithm (Altschul et al. 1997). Sequence alignments and analyses were performed with the Gap and PileUp programs of the Genetics Computer Group package (Madison, WI, U.S.A.). Predictions of subcellular localization and signal peptide analyses were performed with the programs MitoProtII (Claros 1995), PSORT (Nakai and Kanehisa 1992), and ChloroP and TransitP (Center for Biological Sequence Analysis, Department of Biotechnology, Technical University of Denmark) as well as criteria stated by von Heijne et al. (1989).

\section{RT-PCR and Northern analyses.}

Approximately $100 \mu \mathrm{g}$ of total RNA was extracted from 200 to $400 \mathrm{mg}$ of nodules or leaves by a phenol- $\mathrm{LiCl}$ procedure (Verwoerd et al. 1989) using RNaseOut (Life Technologies). RNA concentration and purity was determined by spectrophotometry and visualized by electrophoresis in agarose-formaldehyde gels.

For RT-PCR, $5 \mu \mathrm{g}$ of RNA was primed with oligo $(\mathrm{dT})_{20}$ and reverse transcribed in a total volume of $25 \mu \mathrm{l}$ using Moloney murine leukemia virus reverse transcriptase (Promega). PCR was carried out with gene-specific primers based on internal sequences of Medicago truncatula MnSOD (AW688895), alfalfa FeSOD (AF377344), tobacco MnSOD (X14482), and Arabidopsis FeSOD-2 (P21276). Primers used were as follows. For alfalfa MnSOD: forward 5'-TGTCATCAGCGGCGAAATC-3', reverse 5'-TTCTGCATTAACCTTTTGTATC3'; for alfalfa FeSOD: forward 5'-AAGGAAAGCAGACTTGATG-3', reverse 5'-TCTCCTCCTCTTTCTCCC-3'; for Nicotiana MnSOD: forward 5'-GCGGCTTGCAGACCT-TTT3', reverse 5'-GATAGCGCTATGCAATTTGG-3'; for Arabidopsis FeSOD: forward 5'-AATGAAAAACTCAAAGTAGTG-3', reverse 5'-ACTCACTGTCACTGAAGTC-3'. PCR reactions $(25 \mu \mathrm{l})$ contained 0.75 to $2 \mu \mathrm{l}$ of first-strand cDNA (taken from a resuspension of the cDNA in $100 \mu \mathrm{l}$ of water), $0.2 \mathrm{mM} \mathrm{dNTP}, 1.5 \mathrm{mM} \mathrm{MgCl}{ }_{2}, 0.5 \mu \mathrm{M}$ primers, and 2.5 U of Taq polymerase (Life Technologies) in a $25-\mu \mathrm{l}$ volume. Reactions were initiated by a denaturation step at $94^{\circ} \mathrm{C}$ for $4 \mathrm{~min}$, followed by 25 cycles $\left(94^{\circ} \mathrm{C}\right.$ for $30 \mathrm{~s}, 54^{\circ} \mathrm{C}$ for 45 $\mathrm{s}$, and $72^{\circ} \mathrm{C}$ for $45 \mathrm{~s}$ ), and a final extension step at $72^{\circ} \mathrm{C}$ for $10 \mathrm{~min}$. After amplification, the reaction products were resolved by electrophoresis on a $1 \%$ agarose gel and stained with ethidium bromide. In all cases, preliminary runs were used to verify that the number of amplification cycles was below signal saturation. Images were captured with a GelDoc 2000 DNA Gel Analysis and Documentation System (Bio-Rad, Hercules, CA, U.S.A.) using Quantity One 4.1.1 software (Bio-Rad). 
For Northern hybridization, $10 \mu \mathrm{g}$ of RNA was separated on $1.2 \%$ agarose denaturing (formaldehyde) gels and capillary transferred overnight in $20 \times \mathrm{SSC}(1 \times \mathrm{SSC}$ is $0.15 \mathrm{M} \mathrm{NaCl}$ plus $0.015 \mathrm{M}$ sodium citrate) to Hybond- $\mathrm{N}^{+}$nylon filters (Amersham Pharmacia Biotech, Uppsala, Sweden). RNA was fixed to the filter by exposure to UV light for $5 \mathrm{~min}$ and then at $80^{\circ} \mathrm{C}$ for $2 \mathrm{~h}$. Probes were obtained directly by gel purifying the products of the RT-PCR experiment. Random priming was used to ${ }^{32} \mathrm{P}$-label the probes (Megaprime; Amersham Pharmacia Biotech). Filters were prehybridized at $42^{\circ} \mathrm{C}$ for $2 \mathrm{~h}$ with $50 \%$ formamide, $125 \mathrm{mM}$ sodium phosphate $(\mathrm{pH} 7.2)$, $250 \mathrm{mM} \mathrm{NaCl}, 1 \mathrm{mM}$ EDTA, and 7\% sodium dodecyl sulfate (SDS). Hybridization was performed overnight at the same conditions as for prehybridization with the addition of the ${ }^{32} \mathrm{P}$ labeled probes. The filters were washed successively with $2 \times$ SSC for $10 \mathrm{~min}, 0.5 \times \mathrm{SSC}$ for $10 \mathrm{~min}$, and $0.1 \times \mathrm{SSC}$ for $3 \mathrm{~min}$ (all SSC media contained $0.1 \%$ SDS). Signals were detected with a storage phosphor screen (Imaging Screen-K; Eastman Kodak, Rochester, NY, U.S.A.) and quantified with a Molecular Imager FX (Bio-Rad) using Quantity One 4.1.1 software.

RNA extractions and RT-PCR and Northern experiments were repeated twice using nodules and leaves from two series of plants grown independently. Similar results were obtained, and representative data are shown.

\section{Assay of antioxidant enzymes.}

Samples of nodules or leaves to be used for biochemical analyses were flash frozen in liquid $\mathrm{N}_{2}$ and stored at $-80^{\circ} \mathrm{C}$. All enzymes were extracted at 0 to $4^{\circ} \mathrm{C}$, and activities were measured spectrophotometrically at $25^{\circ} \mathrm{C}$ within the linear region for time and enzyme concentration. Total SOD activity was assayed by inhibition of the reduction of ferric cytochrome $c$ by the superoxide radicals generated with a xanthine-xanthine oxidase system. One unit of SOD activity was defined as the amount of enzyme required to inhibit the reduction of ferric cytochrome $c$ by $50 \%$ (McCord and Fridovich 1969). A low concentration of KCN $(10 \mu \mathrm{M})$ was included in the assay medium of total SOD to inhibit mitochondrial cytochrome $c$ oxidase, without affecting $\mathrm{CuZnSOD}$ activity. To assay $\mathrm{KCN}$-insensitive SOD activity, the final $\mathrm{KCN}$ concentration was increased to $3 \mathrm{mM}$. Boiled extracts showed $<4 \%$ residual SOD activity.

The isozymic pattern of SODs in nodule and leaf extracts was analyzed by activity staining following electrophoresis on nondenaturing polyacrylamide gels $(0.75 \mathrm{~mm}$ thick, $15 \%$ resolving gel, and 4\% stacking gel). The activity stain was based on the inhibition by SOD of the reduction of nitroblue tetrazolium by superoxide radicals generated photochemically (Beauchamp and Fridovich 1971). Identification of isozymes was based on the differential inhibition of SOD activity on gels preincubated with $3 \mathrm{mM} \mathrm{KCN}$ or $5 \mathrm{mM} \mathrm{H}_{2} \mathrm{O}_{2}$ for $1 \mathrm{~h}$. Isozymes were quantified by densitometry with software from the National Institutes of Health.

APX, GPX, and catalase were extracted with optimized media, essentially as described by Gogorcena et al. (1995). APX and catalase activities were assayed following the disappearance of ascorbate at $290 \mathrm{~nm}$ (Asada 1984) and $\mathrm{H}_{2} \mathrm{O}_{2}$ at $240 \mathrm{~nm}$ (Aebi 1984), respectively. GPX activity was measured following the oxidation of pyrogallol at $430 \mathrm{~nm}$ with preincubation for $5 \mathrm{~min}$ with $0.5 \mathrm{mM}$-chloromercuriphenylsulfonic acid (Amako et al. 1994). Because APX may also catalyze pyrogallol oxidation to some extent, $p$-chloromercuriphenyl-sulfonic acid was included in the assay medium to inactivate APX and thus ensure the accurate measurement of GPX activity.

\section{Statistical analyses.}

Six series of plants grown independently under identical environmental conditions were required to obtain sufficient nodule and leaf material. Each series comprised plants of all four lines. All measurements were made on plants belonging to at least two series and were pooled for statistical analysis. All data were subjected to analysis of variance and, when significant, means were compared with the Duncan's multiple range test. The number of samples used for the calculation of the means is stated in each table. Experiments to analyze gene expression by RT-PCR and Northern blot were performed in duplicate, each replicate corresponding to extracts of nodules and leaves from two series of plants.

\section{ACKNOWLEDGMENTS}

This work was supported by grant 2FD97-1101 from the Comisión Interministerial de Ciencia y Tecnología and the European Commission and by grant PB98-0522 from the Dirección General de Investigación Científica (Spain). The Institute of Grassland and Environmental Research is grant aided by the Biotechnology and Biological Sciences Research Council. M. C. Rubio was the recipient of a predoctoral fellowship from the Ministry of Education and Culture (Spain). M. C. Rubio and J. Ramos also were supported by contracts on grant 2FD97-1101. We thank G. Rodríguez for help with harvesting plant material, I. IturbeOrmaetxe for help with Figure 4, and J. F. Moran for help with Figure 6.

\section{LITERATURE CITED}

Aebi, H. 1984. Catalase in vitro. Methods Enzymol. 105:121-126.

Altschul, S. F., Madden, T. L., Schaffer, A. A., Zhang, J., Zhang, Z., Miller, W., and Lipman, D. J. 1997. Gapped BLAST and PSI-BLAST: A new generation of protein database search programs. Nucleic Acids Res. 25:3389-3402.

Amako, K., Chen, G. X., and Asada, K. 1994. Separate assays specific for ascorbate peroxidase and guaiacol peroxidase and for the chloroplastic and cytosolic isozymes of ascorbate peroxidase in plants. Plant Cell Physiol. 35:497-504.

Asada, K. 1984. Chloroplasts: Formation of active oxygen and its scavenging. Methods Enzymol. 105:422-429.

Beauchamp, C., and Fridovich, I. 1971. Superoxide dismutase: Improved assays and an assay applicable to acrylamide gels. Anal. Biochem. 44:276-287.

Becana, M., Moran, J. F., and Iturbe-Ormaetxe, I. 1998. Irondependent oxygen free radical generation in plants subjected to environmental stress: Toxicity and antioxidant protection. Plant Soil 201:137-147.

Bridges, S. M., and Salin, M. L. 1981. Distribution of iron-containing superoxide dismutase in vascular plants. Plant Physiol. 68:275-278.

Bowler, C., Slooten, L., Vandenbranden, S., De Rycke, R., Botterman, J., Sybesma, C., Van Montagu, M., and Inzé, D. 1991. Manganese superoxide dismutase can reduce cellular damage mediated by oxygen radicals in transgenic plants. EMBO J. 10:1723-1732.

Bowler, C., Van Camp, W., Van Montagu, M., and Inzé, D. 1994. Superoxide dismutase in plants. Crit. Rev. Plant Sci. 13:199-218.

Claros, M. G. 1995. MitoProt, a Macintosh application for studying mitochondrial proteins. Comp. Applic. Biosci. 11:441-447.

Christou, P. 1994. The biotechnology of crop legumes. Euphytica 74:165-185.

Dalton, D. A., Joyner, S. L., Becana, M., Iturbe-Ormaetxe, I., and Chatfield, J. M. 1998. Antioxidant defenses in the peripheral cell layers of legume root nodules. Plant Physiol. 116:37-43.

del Río, L. A., Sandalio, L. M., Palma, J. M., Bueno, P., and Corpas, F. J. 1992. Metabolism of oxygen radicals in peroxisomes and cellular implications. Free Radic. Biol. Med. 13:557-580.

Gogorcena, Y., Iturbe-Ormaetxe, I., Escuredo, P. R., and Becana, M 1995. Antioxidant defenses against activated oxygen in pea nodules 
subjected to water stress. Plant Physiol. 108:753-759.

Gogorcena, Y., Gordon, A. J., Escuredo, P. R., Minchin, F. R., Witty, J. F., Moran, J. F., and Becana, M. 1997. $\mathrm{N}_{2}$ fixation, carbon metabolism, and oxidative damage in nodules of dark-stressed common bean plants. Plant Physiol. 113:1193-1201.

Herrera-Estrella, L., Depicker, A., Van Montagu, M., and Schell, J. 1983. Expression of chimeric genes transferred into plant cells using a Tiplasmid-derived vector. Nature 303:209-213.

Horvath, B., Heidstra, R., Lados, M., Moerman, M,. Spaink, H. P. Promé, J. C., van Kammen, A., and Bisseling, T. 1993. Lipo-oligosaccharides of Rhizobium induce infection-related early nodulin gene expression in pea root hairs. Plant J. 4:727-733.

Kurepa, J., Van Montagu, M., and Inzé, D. 1997. Expression of sodCp and $\operatorname{sodB}$ genes in Nicotiana tabacum: Effects of light and copper excess. J. Exp. Bot. 48:2007-2014.

Matamoros, M. A., Moran, J. F., Iturbe-Ormaetxe, I., Rubio, M. C., and Becana, M. 1999. Glutathione and homoglutathione synthesis in legume root nodules. Plant Physiol. 121:879-888.

McCord, J. M., and Fridovich, I. 1969. Superoxide dismutase: An enzymic function for erythrocuprein (hemocuprein). J. Biol. Chem. 244: 6049-6055.

McKersie, B. D., Bowley, S. R., and Jones, K. S. 1999. Winter survival of transgenic alfalfa overexpressing superoxide dismutase. Plant Physiol. 119:839-847.

McKersie, B. D., Murnaghan, J., Jones, K. S., and Bowley, S. R. 2000. Iron-superoxide dismutase expression in transgenic alfalfa increases winter survival without a detectable increase in photosynthetic oxidative stress tolerance. Plant Physiol. 122:1427-1438.

Nakai, K., and Kanehisa, M. 1992. A knowledge base for predicting pro- tein localization sites in eukaryotic cells. Genomics 14:897-911.

Ogawa, K., Kanematsu, S., and Asada, K. 1996. Intra- and extra-cellular localization of "cytosolic" superoxide dismutase in spinach leaf and hypocotyl. Plant Cell Physiol. 37:790-799.

Puppo, A., Dimitrijevic, L., and Rigaud, J. 1982. Possible involvement of nodule superoxide dismutase and catalase in leghemoglobin protection. Planta 156:374-379.

Scandalios, J. G. 1993. Oxygen stress and superoxide dismutases. Plant Physiol. 101:7-12.

Schinkel, H., Streller, S., and Wingsle, G. 1998. Multiple forms of extracellular superoxide dismutase in needles, stem tissues and seedlings of Scots pine. J. Exp. Bot. 49:931-936.

Sevilla, F., López-Gorgé, J., and del Río, L. A. 1982. Characterization of a manganese superoxide dismutase from the higher plant Pisum sativum. Plant Physiol. 70:1321-1326.

Van Camp, W., Bowler, C., Villarroel, R., Tsang, E. W. T., Van Montagu, M., and Inzé, D. 1990. Characterization of iron superoxide dismutase cDNAs from plants obtained by genetic complementation in Escherichia coli. Proc. Natl. Acad. Sci. USA 87:9903-9907.

Van Camp, W., Capiau, K., Van Montagu, M., Inzé, D., and Slooten, L. 1996. Enhancement of oxidative stress tolerance in transgenic tobacco plants overproducing Fe-superoxide dismutase in chloroplasts. Plant Physiol. 112:1703-1714.

Verwoerd, T. C., Dekker, B. M. M., and Hoekema, A. 1989. A smallscale procedure for the rapid isolation of plant RNAs. Nucleic Acids Res. 17:2362.

von Heijne, G., Steppuhn, J., and Herrmann, R. G. 1989. Domain structure of mitochondrial and chloroplast targeting peptides. Eur. J. Biochem. 180:535-545. 